\title{
Potentials of digital approaches in a tourism industry with changing customer needs - a quantitative study
}

\author{
Felix Häfner \\ Aalen University of Applied \\ Sciences, Beethovenstr. 1, 73430 \\ Aalen, Germany \\ Email: kmu@hs-aalen.de
}

\author{
Ralf-Christian Härting \\ Aalen University of Applied \\ Sciences, Beethovenstr. 1, 73430 \\ Aalen, Germany \\ Email: ralf.haerting@hs-aalen.de
}

\author{
Raphael Kaim \\ Aalen University of Applied \\ Sciences, Beethovenstr. 1, 73430 \\ Aalen, Germany \\ Email: raphael.kaim@hs-aalen.de.
}

\begin{abstract}
In recent years, the tourism industry has been undergoing a period of transformation, not least due to innovative and disruptive business models entering the market. Companies are increasingly focusing on customer needs and try to meet them with digital approaches. The early recognition of rapidly changing needs and their reactions is challenging. This paper examines four factors influencing the potentials of the changing customer needs and ongoing digitization in the tourism industry. A hypothesis model developed in previous qualitative research is examined in this paper with a quantitative approach using structural equation modeling. 157 responses from the target group were analyzed to test the factors digital marketing, data mining, digital services and online travel communities. The results of this paper show that digital marketing and data mining have a positive as well as highly significant influence on the potentials of digital approaches in a tourism industry with changing customer needs.
\end{abstract}

\section{INTRODUCTION}

$\mathrm{N}$ OWADAYS innovation brings fewer material products and much more digital services and processes which optimize and expand the value-added process as a result of digitization. The Internet serves as a primary source of information, with great importance also in the tourism industry. Modern digital business models are establishing on the market and contain significant advantages over traditional business models [1]. Electronic data transmission is particularly suited for this purpose, allowing processes to be presented with lower costs and more efficiently [2].

Digital booking channels and services make it easier for people to access a wide variety of offers directly via digital channels. These channels are important to get in touch with the client right at the beginning of the customer journey [11]. In terms of changing customer needs through digitization [4], mobile devices have taken an essential position. They enable not only the gathering of information, but also booking and purchasing of touristic products during the journey [5].

This study essentially refers to the changing customer needs due to digitization in tourism in German-speaking countries. Digitized processes in tourism are progressively influences

This work was not supported by any organization by new technological concepts as Big Data, Cloud- and Mobile Computing, Internet of Things (IoT) or Social Software [6]. In order to fully exploit the potential of digitization, enterprises in tourism have to adapt new digital approaches. The expansion of digital technologies enables the emergence of new business processes or even entire business models [7].

In addition, digitization has a large number of definitions, depending on the dimensions. For example, the presentation and provision of content on websites, sales channel functions (e-commerce) or business process integrations, so-called ebusiness, right up to the already mentioned new business models with virtual products or services are specifically defined [6]. The World Tourism Organization (UNWTO) defines tourism as "activities of persons travelling to and staying in places outside their usual environment for a period not exceeding one year without interruption for leisure, business or certain other purposes". The definition shows that tourism involves a wide range of activities, including travel preparation, arrival and stay at the destination itself as well as the return. The follow-up of the trip, even if it takes place at home again, is part of the concept [8]. An additional feature, which touches the tourism industry especially, is the emotionality of its customers [3]. For a better understanding of this change, the needs of a tourist can be systematically divided into categories [9]. One of the most widespread and fundamental considerations emerges from Maslow needs pyramid. The classification is made according to their urgency [10]. The current change, mostly influenced by social media, shifts the structures with regard to the satisfaction of needs, so-called group dynamic effects. This leads to an increased need and subsequent purchase. It also has an impact on tourism industry [11]. In most cases, the form of tourism today is pleasure and thus the highest level of the Maslow pyramid as a motive of recognition and prestige [8].

The paper is structured as follows: In the next section the research design and methodology are presented. Then the results are presented and compared with the previous qualitative study [12]. The paper concludes with the limitations and an outlook on potential further research. 


\section{RESEARCH AND METHODOLOGY}

In this chapter the authors present hypotheses derived from current international literature and an existing qualitative study [12]. The data collection of the preceding qualitative study is based on semi structured expert interviews. Using the Grounded Theory approach, important determinants could be worked out. Based on this, a quantitative study using structural equation modelling is conducted to validate the previous results. After the design the research method is defined with its data collection and analysis process.

\section{A. Research Design}

In order to work out the potentials of changing customer needs in a digital world in tourism, the investigated influences were collated in a hypotheses model. Potentials in tourism can arise from new technologies and thus a change in customer needs. On the one hand, the overall view is important to see how customers assess the situation. On the other hand, various probability-based programs can be used to calculate the influence of differently selected determinants on the research question. The model with its results is shown in figure 1.

On consideration to the mentioned research design, four determinants were identified and evaluated which are described as follows. The investigation of the influence on the research question shows that various digital technologies offer significant potential. It seems to be possible in the future to meet changing customer needs on the basis of digitization in tourism. The results of the structural equation model are explained in the following chapter using the determinants considered and based on the existent qualitative study by Reichstein and Härting [12].

\section{H1: Digital Services contain potential due to changing} customer needs in a digital world in tourism.

Thanks to mobile technologies, actions can be carried out, information retrieved or trips booked and changed at any time and any location. The more individually the customer receives the information he is looking for, the faster and better he can be advised by digital services. Broad contact and information possibilities on the part of the companies offer the customer the satisfaction of individual needs [13]. In every stage of a journey tourists needs information, which is usually available on the Internet. For companies, very good digital services for providing information can be an advantage on the market. In combination with new technologies (e.g. Virtual Reality) to provide the best digital information and collecting data in the same time, digital services will be an important element in the future [14].

H2: Digital Marketing holds potential due to changing customer needs in a digital world in tourism.

With regard to research on digital marketing in tourism, some online platforms deserve special mention. The result of a survey from 2017 examined the most important social media for companies. With over $60 \%$, Facebook is the most important social media platform, followed by LinkedIn and Instagram [15]. In this context, the trend is also towards persuasive influencers and bloggers. But also people how know each other from real life influence another through social media. The phenomenon of Web 2.0 is accompanied by a change in the market in which customers are increasingly integrated into processes of companies in order to participate actively.

H3: Data Mining shows potentials due to changing customer needs in a digital world in tourism.

Data mining is the process of identifying correlations and patterns from collected data that provide new insights. This requires large amounts of data. The MIT Technology Review sees data mining as one of the ten emerging technologies that can change the world [16]. The absolute majority of tourism customers (93\%) visit tourism specific websites and leave evaluable data before the trip [17]. Companies in tourism sector have huge amounts of data at their disposal which can be used in order to generate helpful insights. With intelligent use of the gained information, there is a possibility to improve strategies and achieve competitive advantages.

H4: Potential due to changing customer needs in a digital world in tourism is contained in Online Travel Communities.

Before a trip, tourists like to inquire in designated online travel forums in order to get information about a certain destination. Impressions, experiences and exchange with other travelers seem to be very credible and are often collected in these forums. Providers can use the information on the platform to make the tourist experience increasingly more pleasant. The exchange between customers creates trust and clarity [18].

According to the literature review, all selected determinants have a positive effect on the research question and thus represent potential.

\section{B. Research Methods and Data Collection}

The research method in the form of a quantitative survey was chosen for various reasons. A subsequent quantitative study can be optimally used for testing and validating hypotheses [19]. The open source software Lime Survey was selected to conduct the survey. The study is intended to provide information in order to identify and exploit potentials in tourism.

There is a sample of 157 usable answers collected from the respondents $(n=157)$. The data was collected over a period of three months in summer 2019. Participants for the survey were contacted personally and by telephone before a link to the survey was sent. Furthermore, social networks and platforms were used to draw the attention of groups with appropriate topics. $70 \%$ of the participants in the online 
survey were younger than 38 years. Only just under $8 \%$ belong to the age group older than 58 years and tend to have less affinity with the Internet. The different genders are evenly distributed among the participants of the survey $(60 \%$ female and $40 \%$ male). What may well affect tourism is the family situation. $30 \%$ of the interviewees have children in the household, which influences the holiday planning and possibly leads to other priorities.

In order to investigate the effects of the determinants, the respondents could apply with five different characteristics. The Likert scale has a range from one to five (1 total agreement to 5 total disagree). To analyse the set-up hypotheses and the collected data sets, structural equation modelling (SEM) was performed. With the analysis tool SmartPLS the influence of constructs on the research question, whether there is potential of changing customer needs in tourism against the background of a digital world, can be tested. Before hypotheses can be confirmed or disproved, typical quality criteria must be checked. Indicators of the quality are Composite Reliability (CR), Cronbach's Alpha (CA) and Average Variance Extracted (AVE) [21].

\section{RESULTS}

The relationships between different variables can be calculated with SEM [20]. SEM is seen as a second generation of multivariate analysis to provide a deeper insight into the analysis of the different relationships. The measurement model validates the latent variables and the structural equation model analyses the relationships between the research model and the latent variables [20].

\section{A. Results of the SEM}

After the data sets of the empirical sample had been evaluated with the analysis tool SmartPLS, the following results turned out (Figure 1).

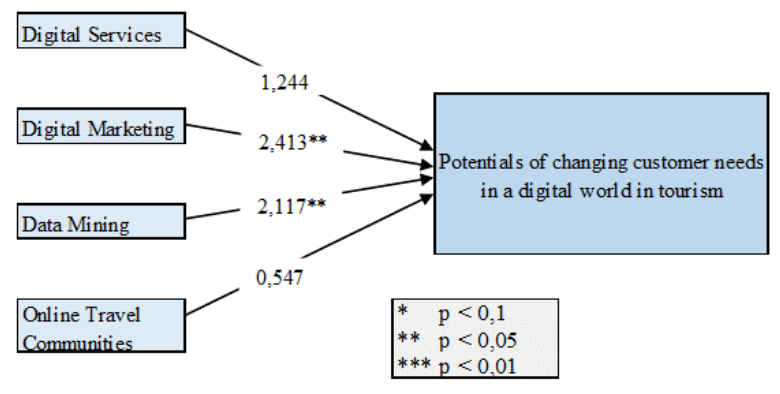

Fig. 1 Structural Equation Model

Due to the very diverse tourism activities described at the beginning, some minor influences that are not included in the model influence the result of the evaluation. Nevertheless, the coefficient of determination $\mathrm{R}^{2}$ is given as 0.247 for the model and is therefore declared sufficient according to Chin [22]. According to the analysis with SmartPLS, a significant potential for changing customer needs in tourism is found in two of the four evaluated determinants which have a P-Value with $\mathrm{p}<0,05$. In summary, the determinants digital marketing $(2,413)$ and data mining $(2,117)$ can be described as significant potentials $(\mathrm{p}<0,05)$ with a highly positive impact. The determinant digital marketing shows an original sample of 0,184 and an average sample value of 0,185 . These values are slightly below the target of 0,200 which describes the indicator relevance and significance [22]. As the standard deviation is the lowest in the whole results, respondents have nearly always the same opinion of the hypotheses. Global networks of social media platforms have the potential to change the business-to-customer relationship. Therefore, they offer great opportunities in terms of digital possibilities to meet changing customer needs. Data mining has even better results in original sample and average sample value. With results of 0,212 and 0,236 the target of 0,200 is reached, which shows good modeling and confirms the significance level. Data mining forms the basis for the recording of changes in customer needs and the use of technologies that can provide the customer with specifically tailored models.

The determinants digital services $(1,244)$ and online travel communities $(0,547)$ miss a high significant level in the results. Digital services miss the target value in original sample and average sample value with 0,097 and 0,126. The quality of these values is somewhat weak. The reason for this could be that the definition of digital services is not understood uniformly. The values of the online travel communities are even weaker with 0,043 and 0,042 . The weak result in the T-statistics and the relatively high P-value confirm the weak influence on the research question. Detailed information about the structural equation model and the influence of the determinants is shown in table 1 .

A consideration of the quality criteria is important to prove the consistency of the model. Overall, the structural equation model achieves good values with respect to the Homburg quality criteria [21]. Cronbachs Alpha (CA) measures the internal consistency of the model. The target value is $>0,7$. Composite Reliability (CR) shows the reliability of the determinants on the research question. It is declared as good with a value $>0,6$. Also the Average Variance Extracted (AVE) shows the quality of different paths. It measures the fitting of the indicators with the determinants. If the indicators describe the associated construct well, the value is $>0,5$. The investigated determinants, digital services, digital marketing and online travel forums, show very good values across all three quality criteria, which are attributed to the high quality of the model. The construct digital services has high values with 0,824 for $\mathrm{CR}$ and 0,721 for CA. The value for AVE is also in the target with 0,545 . Even better values in quality criteria is reached in the construct digital marketing. Values 0,869 for $\mathrm{CR}, 0,805$ for $\mathrm{CA}$ and 0,628 for AVE shows a clean path from the indicators over the construct to the research 
TABLE I.

RESULTS OF THE STRUCTURAL EQUATION MODEL

\begin{tabular}{|l|l|l|l|l|l|}
\hline \multicolumn{1}{|c|}{ Determinants } & Original Sample & $\begin{array}{c}\text { Average Sample } \\
\text { Value }\end{array}$ & $\begin{array}{c}\text { Standard } \\
\text { Deviation }\end{array}$ & T-Statistics & $\begin{array}{c}\text { Turing } \\
\text { complete }\end{array}$ \\
\hline Digital Services & 0,097 & 0,126 & 0,078 & 1,244 & 0,214 \\
\hline Digital Marketing & 0,184 & 0,185 & 0,076 & 2,413 & 0,016 \\
\hline Data Mining & 0,212 & 0,236 & 0,100 & 2,117 & 0,035 \\
\hline $\begin{array}{l}\text { Online Travel } \\
\text { Communities }\end{array}$ & 0,043 & 0,042 & 0,079 & 0,547 & 0,585 \\
\hline
\end{tabular}

question. The construct online travel communities has the highest value for $\mathrm{CR}$ with 0,902 and for $\mathrm{CA}$ with 0,855 . The AVE with a value of 0,698 shows an excellent description of the construct through indicators. Only data mining weakens the model somewhat in the values of Cronbachs Alpha with 0,604 and the recorded average variance extracted which is slightly below the target value with 0,430 . The value of CR matches the quality with 0,735 . The structural equation model of this study can thus be confirmed with good quality. All values of the quality criteria are summarized in table 2 .

The answers given by the interviewees are very clear. Almost 100 people (61\%) fully agree with the hypothesis of using digital services as a source of information. Almost $40 \%$ of the respondents said that they are strongly influenced by social media when planning their holidays. Half of them agree completely. The majority of respondents indicated that they were aware of the benefits of collecting data from companies. The analysis of the survey showed that almost half of the respondents are active in online travel forums before, during or after their holidays.

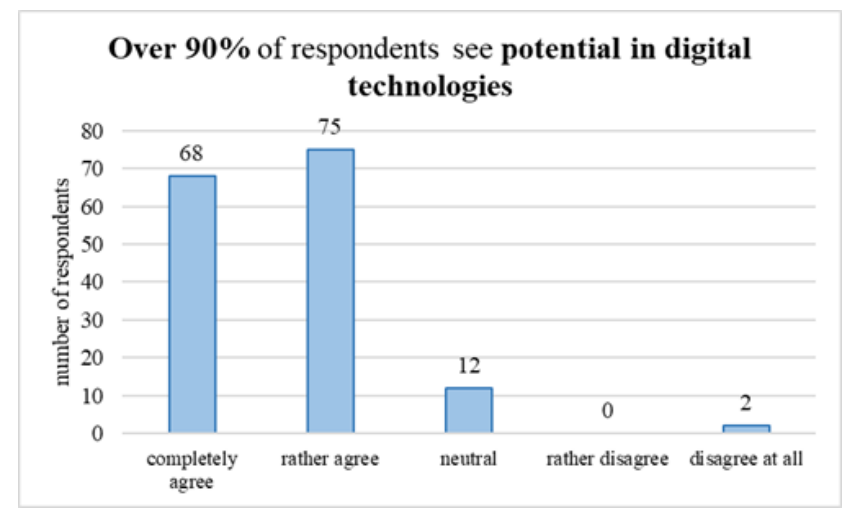

Fig. 2 Potential in digital technologies

Figure 2 refers directly to the research question. The respondents were asked to answer the question, if they see potential in digital technologies in a tourism industry with changing customer needs. More than $90 \%$ of the survey participants agree with the hypothesis that there is a potential for digital technologies in tourism. The distribution of the answers makes clear that the majority agrees with this major hypothesis. Only just under $8 \%$ of those surveyed disagree with the hypothesis, but do not reject it either.

\section{B. Comparison with the qualitative study}

The elaborated qualitative study confirms all four determinants as influential and significant. The differences between the two studies lie in the fact that experts from various companies were interviewed on the one hand and customers on the other. Two sides, each of which takes a different view at the situation. Differences in the studies can be seen in the determinants considered in the field of digital services and online travel forums. Digital marketing and data mining were perceived as significant in both studies. The difference that digital services in the quantitative study do not show a significant influence on the research question could have these reasons: On the one hand, companies provide their own services that can be used by customers. Society uses general tools to obtain information. On the other hand, companies might attach importance to the channel through which customers obtain information, e.g. accommodation. Accordingly, customers attach great importance to a good information supply and selection of offers. The channel ultimately used to contact the company is not a priority. The situation is somewhat different for the determinant of online travel forums. Companies place a strong emphasis on the data that can be generated because it is usually honest and reflects a comprehensive picture of the customer experience. In contrast, the quantitative study found that while customers use online travel forums for information purposes, very few respondents share their opinions and experiences.

\section{CONCLUSION}

The results show specific potentials in the field of digital marketing and data mining. Both determinants have a significant influence on the research question. There are new opportunities to exploit market potential and competitive advantages. Digital marketing provides different approaches to address specific target groups and satisfy customer needs at the right place in the right time. Data mining forms an essential basis for the existence of modern companies. With large amounts of data (Big Data) innovative potentials of digital approaches can be exploited effectively. Once the future customer needs have been identified, the challenge lies in the fast reaction time of the companies. The design of the processes themselves has a great influence. Digitization promotes flexibility and fast response cycles. The better the 
TABLE II.

QUALITY CRITERIA OF THE STRUCTURAL EQUATION MODEL

\begin{tabular}{|l|l|l|l|}
\hline \multicolumn{1}{|c|}{ Determinants } & Composite Reliability (CR) & Cronbachs Alpha (CA) & Average Variance Extracted (AVE) \\
\hline Digital Services & 0,824 & 0,721 & 0,545 \\
\hline Digital Marketing & 0,869 & 0,805 & 0,628 \\
\hline Data Mining & 0,735 & 0,604 & 0,430 \\
\hline Online Travel Communities & 0,902 & 0,855 & 0,698 \\
\hline
\end{tabular}

implementation of new digital approaches is promoted in companies; the more potential is available to identify and respond to customer needs.

The elaboration of this study is subject to a certain limitation by an empirical investigation in the form of quantitative research. The data sets that could be used for the investigation were limited to $\mathrm{n}=157$ persons, who act as customers in the tourism industry and were raised online. That is why the results do not allow unrestricted conclusions about the population. This can happen, even though a balanced data collection has been ensured. Results in other European countries or international may differ from the evaluations in this investigation.

Further studies in the field of digitization in tourism are quite conceivable if the responsible parameters are extended. A data collection in Europe could show some differences from this evaluation. A consideration of customer needs in a digital world in tourism, which collects data with the help of quantitative research in companies, could represent an increased added value with a different point of view. It would be interesting to compare the results in order to find out, how much potential in communication between customers and companies has not yet been fully exploited. The separate consideration of digital and conventional business models is also conceivable. That might give the opportunity of developing various, as yet untapped potentials in the tourism industry.

\section{REFERENCES}

[1] Bharadwaj, Anandhi et al. (2013): "Digital Business Strategy: Toward a Next Generation of Insights". In: MIS Quarterly, vol. 37, no. 2, 2013, pp. 471-482.

[2] Härting, R.-C.; Reichstein, C.; Schad, M. (2018): "Potentials of Digital Business Models - Empirical investigation of data driven impacts in industry", in: Robert J. Howlett et. al. (2018), KnowledgeBased and Intelligent Information \& Engineering Systems, KES-2018, Elsevier B.V. 2018, Vol. 126, pp. 1495-1506.

[3] Buhalis, D. (2003): ,eTourism - Information technology for strategic tourism management", Essex: Prentice Hall.

[4] Johnson, D. S., Bharadwaj B. (2005): "Digitization of selling activity and sales force performance: An empirical investigation". Journal of the Academy of Marketing Science, 33(1), pp. 3-18.

[5] Kim, H.; Law, R. (2015): "Smartphones in Tourism and Hospitality Marketing. A Literature Review". In: Journal of Travel \& Tourism Marketing 32 (6), pp. 692-711.

[6] Härting, R.-C.; Reichstein, C.; Härtle, N. (2017): "Potentials of Digitization in the Tourism Industry - Empirical Results from German Experts". In: Abramowicz, W., Lecture Notes in Business Information Processing, Springer 2017, Vol. 288, pp 165-180.

[7] Härting, R.-C.; Reichstein, C.; Haarhoff, R.; Härtle, N.; Stiefl, J. (2019): "Driver to Gain from Digitization in the Tourism Industry -
Insights from South African Tourism Experts", in: Yang, X.-S., et. al. (Eds.), Advances in Intelligent Systems and Computing, ICICT 2018, AISC Springer 2019, Vol. 3, pp. 293-306.

[8] Leiper, N. (1979): "The framework of tourism." In: Annals of Tourism Research 6 (4), pp. 390-407.

[9] Timoshenko, A.; Hauser, J. (2019): "Identifying Customer Needs from User-Generated Content”. In: Marketing Science 38 (1), pp. 120.

[10] Mitchell, V.; Moudgill, P. (1979): “Measurement of Maslow's need hierarchy". In: Organizational Behavior and Human Performance 16 (2), pp. 334-349.

[11] Gretzel, U. (2011): "Intelligent systems in tourism". In: Annals of Tourism Research 38 (3), pp. 757-779.

[12] Reichstein, C.; Härting, R.-C. (2018): "Potentials of changing customer needs in a digital world - a conceptual model and recommendations for action in tourism". In: Procedia Computer Science 126, pp. 1484-1494.

[13] Thirumalai, S.; Sinha, K. (2011): "Customization of the online purchase process in electronic retailing and customer satisfaction". An online field study. In: Journal of Operations Management 29 (5), pp. 477-487.

[14] Polukhina, A.; Arnaberdiyev, A.; Tarasova, A. (2019): "Leading technologies in tourism. Using blockchain in TravelChain project". In: Proceedings of the 3rd International Conference on Social, Economic, and Academic Leadership (ICSEAL 2019). Prague, Czech Republic, 23.03.2019 - 24.03.2019. Paris, France: Atlantis Press.

[15] Rabe, L. (2019): „Welche Social-Media-Plattform ist für $\mathrm{Ihr}$ Unternehmen am wichtigsten?" Ed. Social Media Examiner. Online available https://de.statista.com/statistik/daten/studie/463928/umfrage/wichtigs te-social-media-plattformen-fuermarketingverantwortliche, last checked on 21.08.2019.

[16] Larose, D. (2005): "Discovering knowledge in data. An introduction to data mining". Hoboken, N.J: Wiley-Interscience.

[17] Dittert, M.; Härting, R. C.; Reichstein, C.; Bayer C. (2017): “A Data Analytics Framework for Business in Small and Medium-Sized Organizations", In: I. Czarnowski, R. Howlett, L. Jain. (Ed.), Smart Innovation, Systems and Technologies - Proceedings of the 9th KESIDT 2017 - Part II, Springer 2017, Vol. 73, pp.169-181.

[18] Cheng, X.; Fu, S.; Sun, J.; Bilgihan, A.; Okumus, F. (2019): “An investigation on online reviews in sharing economy driven hospitality platforms. A viewpoint of trust". In: Tourism Management 71, pp. 366-377.

[19] Kothari, C. R. (2004): "Research methodology. Methods \& techniques". 2nd rev. ed. New Delhi: New Age International (P) Ltd. Publishers.

[20] Rhemtulla, M.; Brosseau-Liard, P.; Savalei, V. (2012): "When can categorical variables be treated as continuous? A comparison of robust continuous and categorical SEM estimation methods under suboptimal conditions". In: Psychological Methods 17 (3), pp. 354373.

[21] Homburg, C.; Baumgartner, H. (1995): „Beurteilung von Kausalmodellen. Bestandsaufnahme und Anwendungsempfehlungen". In: MAR 17 (3), pp. 162-176.

[22] Chin, W. (1998): "The Partial Least Squares Approach for Structural Equation Modeling”. In: Modern Methods for Business Research, Psychology Press, pp.295-336.. E. Haskell and C. T. Case, "Transient signal propagation in lossless isotropic plasmas (Report style)," USAF Cambridge Res. Lab., Cambridge, MA Rep. ARCRL-66-234 (II), 1994, vol. 2. 